\title{
Shipping Demand Scheme Modeling and Measurement Based on Task Constraints
}

\author{
Yongtao $\mathrm{Yu}^{1,}$,, Ying Ding ${ }^{2}$ \\ ${ }^{1}$ Naval Academy of Armament, Beijing, china, 100161 \\ ${ }^{2}$ Beijing Sino-Ocean JIYE Propetry Management CO., LTD, Beijing, china, 100038 \\ à_yt128@aliyun.com
}

Keywords: Shipping demand scheme, Task constraints, Integer Programming

\begin{abstract}
Shipping is an effective solution to the current flowing bulk goods. Because it deficiencies that the shipping demand scheme is determined by experience. It proposed building demand integer programming model based on task constraints, estimated shipping demand scheme. Firstly, determine the sensitivity analysis of factors affecting shipping. Secondly, enter the entity data transport task, using branch and bound solution for solving integer programming model estimates, get shipping demand preliminary initial scheme set. Again according to the rules of formation of bound ship, screening and correction initial demand scheme set, determining shipping demand scheme.
\end{abstract}

\section{Introduction}

Shipping demand scheme is the fundamental basis of modern large-scale logistics project decisions. Key factors of influence shipping demand calculation are transport objects, sailing conditions and ship formation rules. It can be divided into three steps to resolve the problem of shipping demand calculation. The first is the task analysis. Transportation tasks in three areas affecting demand calculation. Physical properties of transport object restrictions or impact on transport, including transport object weight, volume and dimensions and so on. Routes for the transport restrictions or impact on transport, including the speed, endurance capabilities, and ship net deadweight restrictions and so on. Ship formation restrictions or impact on transport, including differences in the speed and tonnage of ships and so on. Through analysis, transportation tasks to achieve fixed quantification impact on demand calculation. The second is planning estimates. Based on integer programming theory, transport objects and the sailing conditions can be mapped to the constraint of programming model, to build shipping demand calculation integer programming model. According to the specific transport tasks, branch and bound solution can be used for solving integer programming calculation model, to generate the set of demand initial scheme. The third is marshalling adjustments. According formation conditions, exact simulated method can be used to delete the demand initial scheme without meet the ship formation rules, select the applicability demand preliminary scheme, eventually forming shipping demand.

\section{Analysis of Sensitive Factors Influencing the Demand Scheme}

Many of the shipping task requirements, including the type and size of the transport object, the transport time requirements, departure and arrival ports, routes and formations rules. After analysis, the impact of these requirements on the shipping demand calculation can be grouped into three categories factors: Factors transport objects; Factors sailing conditions and Factors formation conditions.

Analysis of Sensitive Factors Transport Object. Impact of transport objects for shipping demand, meaning transport objects (goods, vehicles and personnel, etc.) physical attributes (weight, volume 
and area parameters) restrictions on the transport ship. As the size of the ship's cargo port must meet the loading requirements of transport object. This factor includes two sub-factors: type sub-factor and key loading features sub-factor.

Because many types of transport object, each object has its application class transport ship. As the liquid must be transported by tanker, and Ro/Ro ship can be used to transport vehicles. So here design type sub-factor, to determine the specific types of ships depending on the type of transport objects.

Because any type of object includes loading area, loading volume and load weight of the three parameters, but only one of which is a key characteristic loading parameters, determines whether the ship to bear the transport task. As the key loading features of the vehicle and personnel is the loading area. So here design key loading features sub-factor, to identify viable model of ship based on key loading features of transport object.

Analysis of Sensitive Factors Sailing Conditions. Ships sailing conditions affecting for transport demand, transport routes attribute refers task (voyage and ports, etc.) restrictions on the transport ship. As the ship must have the ability to safe navigation on the route. This factor included four sub-factors: speed sub-factor, load sub-factor, airworthiness sub-factor and endurance sub-factor.

Completed on time is a fundamental requirement of the transport task. Voyage and time for specific tasks, the implementation of the transport speed of the ship also has a corresponding request. As the ship's cruising speed greater than the speed of mission requirements. So here was designed speed sub-factor to characterize influence of the speed limit on a ship model of choice.

Ships can use the task port is the basis of the transport task. This requires transport dock ship safe harbor, and effective use of the port loading facilities. As the ship should meet departure and arrival ports use conditions. So here was designed the load sub-factor to characterize the port limit of the ship model selection.

Ship transport task is completed on the premise that safe sailing on the route. This ability to withstand storms and sea conditions required to perform transport tasks should be higher than usually ship sea state transportation task waters. As the ship can be safe navigate in the seven levels storms conditions. So here was designed the airworthiness sub-factor to characterize influence of the sailing area limit on a ship model of choice.

The nature of the ship to complete the transportation task is to arrive safely at their destinations. Namely transport ship voyage route length should be greater than the transport task. Such as the ability to continue sailing vessels of not less than 3500 sea miles and so on. So here was designed the endurance sub-factor to characterize the airline mileage limit of the ship model selection.

Analysis of Sensitive Factors Formation Conditions. Ships formation conditions affecting for transport demand, ship formations attribute refers task (compiled conditions, etc.) restrictions on the transport ship. As the safety clearance in the formation of the ship can not differ too big. This factor include two sub-factors: marshalling sub-factor and management sub-factor.

Because of different ship types and models, designed in the speed indicator is also different. Ships fleet at sea for speed and pitch, there are stringent requirements. As all ships sailing speed difference is not greater than 3 Knots and so on. So here was designed marshalling sub-factor to determine the feasibility of the ship programmed into the transport fleet.

Because the transport task involving a large number of ships. When demand calculation, should have required an analysis of the distribution of resources in the ship, consumption and scheduling. Such as position of transport ship relative dispersion and so on. So here was designed management sub-factor to determine the economy of the ship programmed into the transport fleet.

\section{Building of Demand Scheme Calculation Model}

Core indicators for the shipping demand are specific model and size of ship to complete the transport task. Because the transportation problem can be abstracted as integer programming problems, so it can choose integer programming as core theory of calculation model. Constructing 
shipping demand integer programming model includes determining object; establish constraints, building models and select solver methods.

Determine the Object of Demand Calculation Model. The fundamental purpose of shipping demand calculation is reasonable and efficient shipping solutions. So we chose the smallest ship $\min \left|f=\sum_{n=1}^{k} N_{n}\right|_{\text {as object of shipping demand integer programming. }}$

Establish Constraints of Demand Calculation Model. Key factors of influence transport demand calculation are transport object, sailing conditions and ship formation rules. So create demand constraint integer programming model based on these key factors.

According to the analysis of Factors transport object in the previous section, may establish its constraints on the transport ship. Ships loaded with a total volume must be greater than the volume of transport objects must be loaded, as $\sum_{n=1}^{k} N_{n} \bullet V_{n} \geq V_{n e}$. Ships loaded with a total weight must be greater than the weight of transport objects must be loaded, as $\sum_{n=1}^{k} N_{n} \bullet \mathrm{T}_{n} \geq \mathrm{T}_{n e}$. Ships loaded with a total area must be greater than the area of transport objects must be loaded, as $\sum_{n=1}^{k} N_{n} \bullet S_{n} \geq S_{n e}$. Ship loading conditions (hatch size, etc.) must to meet the transportation requirements of the object dimensions as $C \mathrm{~T}_{n} \subseteq C \mathrm{~T}_{\text {task }}$.

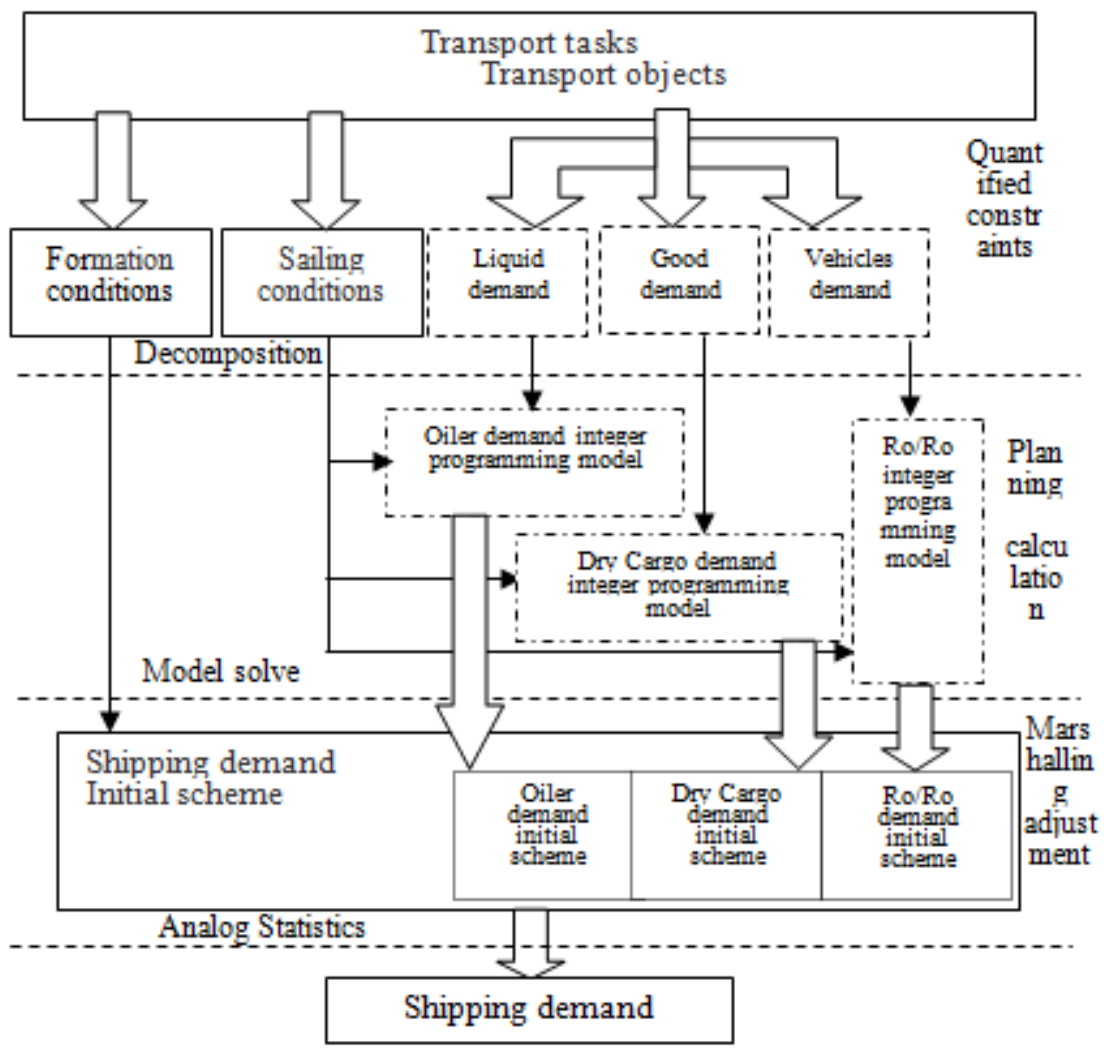

Fig. 1 Shipping demand calculation process.

According to the analysis of Factors sailing conditions in the previous section, we can establish its constraints on the transport ship. Ships sailing conditions (speed, wind strength and endurance, etc.) must to meet the transportation requirements of the sea and routes as $\mathrm{CH}_{n} \subseteq \mathrm{CH}_{\text {task }}$. 
According to the analysis of Factors formation conditions in the previous section, we can establish its constraints on the transport ship. Each cargo each ship loading volume greater than the volume of the assigned transport task object as $V_{i j} \geq V_{\text {taskij }} \quad 0<j<N_{n} \quad 0<i<k$. Each cargo each ship loading weight greater than the weight of the assigned transport task object as $T_{i j} \geq T_{\text {taskij }} \quad 0<j<N_{n} \quad 0<i<k$.

In addition, according to the requirements of practical problems, the scale of transport ships should be non-negative integer, as $N_{1}, \ldots, N_{n} \geq 0$ that is an integer. This is a requirement of non-negative decision variables.

Build Shipping Demand Calculation Integer Programming Model. Based on the above analysis, this can build a shipping demand calculation integer programming model, as shown in Eq. 1.

$$
\begin{aligned}
& \min \left|f=\sum_{n=1}^{k} N_{n}\right| \\
& \sum_{n=1}^{k} N_{n} \bullet V_{n} \geq V_{n e} \\
& \sum_{n=1}^{k} N_{n} \bullet \mathrm{T}_{n} \geq \mathrm{T}_{n e} \\
& \sum_{n=1}^{k} N_{n} \bullet \mathrm{S}_{n} \geq \mathrm{S}_{n e} \\
& V_{i j} \geq V_{\text {taskij }} \quad 0<j<N_{n} \quad 0<i<k \\
& T_{i j} \geq T_{\text {taskij }} \quad 0<j<N_{n} \quad 0<i<k \\
& C \mathrm{~T}_{n} \subseteq C \mathrm{~T}_{\text {task }} \\
& C \mathrm{H}_{n} \subseteq C \mathrm{H}_{\text {task }} \\
& N_{1}, \ldots, \quad N_{n} \geq 0 \\
& N_{1}, \ldots, \quad N_{n} \in I N T
\end{aligned}
$$

Identify Demand Calculation Model Solution. According to shipping demand calculation of the problem is a variable with upper and lower limit of the specific nature of linear programming, branch and bound solution here can choose to solve the programming model to get the shipping demand initial scheme. Specific processes of shipping demand calculation shown in Fig. 1.

\section{Analysis of the Demand Scheme Calculation Case}

Here we choose to measure transport U.S. Marine Corps (USMC) 2nd expedition demand as examples to illustrate how to apply the shipping demand integer programming model to calculate shipping demand. The 2 nd expedition under the jurisdiction of the USMC regimental level ground combat units and service support battalion.

Quantified Constraints. Since the completion of the transport task, requires transportation of all equipment and personnel of the USMC 2nd expedition, and the necessary combat ammunition. So transporting object includes combat vehicles, operational personnel and munitions. Combat vehicles and personnel needed Ro/Ro ship, the key characteristic parameters is the loading area. The common means of transport ammunition is dry cargo ship, the key characteristic parameters for loading volume. After analysis, the USMC 2nd expedition transport conditions can be quantified as follows: 380 vehicles and 15,300 combat personnel (about 9,592.6 tons, necessary loading area of approximately 21,888.8 $\left.\mathrm{m}^{2}\right), 3958.7$ tons of ammunition (19,200,000 various types of missiles and gun shells, necessary loading volume of approximately $\left.14,849.2 \mathrm{~m}^{3}\right)$.

Transportation USMC 2nd expedition sailing conditions: speed not less than 14 Knots, to sail in Class I navigation area; life is not less than 3500 sea miles. 
Transportation USMC 2nd expedition grouping conditions: tonnage difference is not greater than 2000 tons (8,500-10,500 tons); the speed difference is not more than 3Knots.

According to statistics, details of transport ships are shown in Table 1.

Table 1. Availability of transport ships resource table.

\begin{tabular}{|c|c|c|c|c|c|c|c|c|c|}
\hline Model & Type & \begin{tabular}{|c|} 
Displacem \\
ent \\
(Ton)
\end{tabular} & $\begin{array}{l}\text { Payload } \\
\text { (Ton) }\end{array}$ & $\begin{array}{c}\text { Loading } \\
\text { area } \\
(\mathrm{Sn})\end{array}$ & $\begin{array}{l}\text { Loading } \\
\text { volume } \\
(\mathrm{Vn})\end{array}$ & $\begin{array}{l}\text { Speed } \\
\text { (SPn) }\end{array}$ & $\begin{array}{c}\text { Endurance } \\
\text { (En) }\end{array}$ & $\begin{array}{c}\text { Airworthin } \\
\text { ess } \\
\text { (An) }\end{array}$ & hatch size \\
\hline T-AKR9 & $\begin{array}{l}\text { Ro/Ro } \\
\text { Ship }\end{array}$ & 10130 & 8243 & 13178 & & 20.1 & 7800 & I & $4.5 \times 4.1$ \\
\hline T-AKR8 & $\begin{array}{l}\text { Ro/Ro } \\
\text { Ship }\end{array}$ & 21500 & 17735 & 24325 & & 20.1 & 12500 & I & $6.8 \times 5.1$ \\
\hline T-AKR7 & $\begin{array}{l}\text { Ro/Ro } \\
\text { Ship }\end{array}$ & 8973 & 6586 & 11046 & & 16.2 & 6500 & I & $3.8 \times 3.5$ \\
\hline T-AKR3 & $\begin{array}{c}\text { Ro/Ro } \\
\text { Ship }\end{array}$ & 4562 & 3218 & 4272 & & 13.5 & 3500 & I & $2.2 \mathrm{X} 1.8$ \\
\hline T-AE-33 & $\begin{array}{l}\text { dry cargo } \\
\text { ship }\end{array}$ & 18088 & 14586 & & 22846 & 20.1 & 10500 & I & $25.39 \times 13.1$ \\
\hline T-AE-26 & $\begin{array}{l}\text { dry cargo } \\
\text { ship }\end{array}$ & 11404 & 9436 & & 15478 & 20.1 & 8500 & I & $13.4 X 12.1$ \\
\hline T-AK294 & $\begin{array}{l}\text { dry cargo } \\
\text { ship }\end{array}$ & 10000 & 8747 & & 11721 & 19.2 & 7500 & I & $8.5 \times 7.5$ \\
\hline T-LKA115 & $\begin{array}{l}\text { dry cargo } \\
\text { ship }\end{array}$ & 9100 & 6825 & & 8575 & 18.5 & 5500 & I & $7.5 \times 6.5$ \\
\hline
\end{tabular}

Planning Calculation. According to the transport conditions and navigation conditions of transport USMC 2nd expedition identified the constraint, based on four models of dry cargo ship, to transport ammunition to build integer programming model, as shown in Eq. 2.

$$
\begin{aligned}
& \min \left|f=\sum_{n=1}^{4} N_{n}\right| \\
& \sum_{n=1}^{4} N_{n} \bullet \mathrm{V}_{n} \geq 14,849.2 \\
& \sum_{n=1}^{4} N_{n} \bullet \mathrm{S}_{n} \geq 21,888.8 \\
& S P_{n}>14 \quad 0<n<4 \\
& T_{n}>7 \quad 0<n<4 \\
& E_{n}>3500 \quad 0<n<4 \\
& A_{n}>15 \quad 0<n<4 \\
& \text { hatch size } \geq 8 X 7 \\
& N_{1}, \ldots, N_{n} \geq 0 \quad \\
& N_{1}, \ldots, N_{n} \in I N T
\end{aligned}
$$

The use of branch and bound solution for solving Eq. 2, available transport ammunition shipping demand initial scheme, as shown in Table 2.

Table 2. Transport ammunition demand initial scheme.

\begin{tabular}{|c|c|c|c|}
\hline No & transport ammunition demand initial scheme & $\begin{array}{c}\text { Loadable capacity } \\
\text { Ton }\end{array}$ & $\begin{array}{c}\text { Loadable volume } \\
\mathbf{M}^{3}\end{array}$ \\
\hline 1 & T-AE-33 ( 1 ) & 14,586 & 22,846 \\
\hline 2 & T-AE-26 ( 1) & 9,436 & 15,478 \\
\hline 3 & T-AK294 ( 2) & 13,650 & 17,150 \\
\hline
\end{tabular}


Similarly, according to transport conditions and navigation conditions identified constraints, based on four models of Ro/Ro ship, can create vehicles and personnel transport integer programming model. The use of branch and bound solution for solving integer programming model available transport vehicles and personnel demand initial scheme, as shown in Table 3.

Table 3. Transport vehicles and personnel demand initial scheme.

\begin{tabular}{|c|c|c|c|}
\hline \multirow{2}{*}{ No } & $\begin{array}{c}\text { transport vehicles and personnel demand initial } \\
\text { scheme }\end{array}$ & $\begin{array}{c}\text { Loadable capacity } \\
\text { Ton }\end{array}$ & $\begin{array}{c}\text { Loadable area } \\
\mathbf{M}^{2}\end{array}$ \\
\hline 1 & T-AKR9(2) & 16,486 & 26,356 \\
\hline 2 & T-AKR8(1) & 17,735 & 24,325 \\
\hline 3 & T-AKR7(2) & 13,172 & 22,092 \\
\hline 4 & T-AKR9(1) T-AKR7(1) & 14,829 & 24,224 \\
\hline
\end{tabular}

Taking these two demand initial schemes, available transportation USMC 2nd expedition demand initial scheme, contains a total of 12 schemes, as shown in Table 4.

Table 4. Transport USMC 2nd expedition demand initial scheme.

\begin{tabular}{|c|c|c|}
\hline No & transport ammunition & transport vehicles and personnel \\
\hline 1 & T-AE-33 ( 1$)$ & T-AKR9(2) \\
\hline 2 & T-AE-26 ( 1) & T-AKR8 $(1)$ \\
\hline 3 & T-AK294 ( 2$)$ & T-AKR7(2) \\
\hline 4 & & T-AKR9(1) T-AKR7(1) \\
\hline
\end{tabular}

Marshalling Adjustment. According to the formation conditions of transport USMC 2nd expedition (tonnage difference is not more than 2000 tons, the speed difference is not greater than 3), the demand initial scheme needs to be adjusted. First analyze the displacement of the transport ship; because the tonnage is not within the range of 8,500-10,500 tons, excluding does not meet the requirements of the T-AKR8 Ro/Ro ship and T-AE-33 dry Cargo Ship. Finally, the speed transport ships for analysis, because the speed of T-AKR7 Ro/Ro ship is 16.2 Knots, does not meet the conditions for removing.

After adjustment, USMC 2nd expedition shipping demand scheme can to simplify for the two programs, detailed data are shown in Table 5.

Table 5. USMC 2nd expedition shipping demand scheme.

\begin{tabular}{|c|c|c|c|c|c|}
\hline \multirow{3}{*}{ No } & \multicolumn{5}{|c|}{ USMC 2nd expedition shipping demand } \\
\cline { 2 - 6 } & $\begin{array}{c}\text { transport } \\
\text { ammunition }\end{array}$ & $\begin{array}{c}\text { transport vehicles } \\
\text { and personnel }\end{array}$ & $\begin{array}{c}\text { Loadable area } \\
\mathbf{M}^{2}\end{array}$ & $\begin{array}{c}\text { Loadable volume } \\
\mathbf{M}^{3}\end{array}$ & $\begin{array}{c}\text { Loadable capacity } \\
\text { Ton }\end{array}$ \\
\hline 1 & T-AE-26( 1 ) & T-AKR9(2) & 26,356 & 15,478 & 25,922 \\
\hline 2 & T-AK294 (2) & T-AKR9(2) & 26,356 & 17,150 & 30,136 \\
\hline
\end{tabular}

\section{Summary}

Determine the scientific and reasonable shipping demand scheme is an important prerequisite for the efficient use of resources in the ship. The study showed that the process can be based on the analysis of transport objects and navigation constraints, to build shipping demand calculation integer programming model. Based on the analysis of specific transport tasks, branch and bound solution can be used for solving integer programming model to the set of shipping demand initial scheme set. Based on the analysis ship formation rules, adjust the demand initial scheme set to determine shipping demand. So the use of shipping demand calculation integer programming model can provide a viable and practical method to calculate scientific and reasonable shipping demand scheme. In the next step of the study, we will continue to deepen the analysis of particle transport material simulation to improving demand scheme calculation for completeness. 


\section{References}

[1] L. H. Melanie, D. B. Ralph, Concurrent optimization in designing for logistics support, European J. Operational Res. 115(1) (1999) 77-97.

[2] Z. Uzay, H. R. Kaymak, N. V. Lemke, A Sensitivity Analysis Approach to Introducing Weight Factors into Decision Functions in Fuzzy Multicriteria Decision Making, Fuzzy Sets Syst. 97(2) (1998) 169-182.

[3] Z. C. Xu, Equipment Support of Engineering and Management, Defense Industry Press, 2006, 01.

[4] J. L. Su, linear programming theory and model, Science Press, 2003.

[5] J. Hua, Implementation decisions evaluation system - Application of AHP in decision support systems, J. Harbin Inst. Technol. 31(2) (1999) 69-72.

[6] A. Kaplan, D. Orr, An optimum multi echelon repair policy and stockage model, Naval Res. Logist. Q. 32(4) (1985) 551-566.

[7] K. C. Lu, Single-target, multi-target and integer programming, Tsinghai University Press, 1999. 